\title{
Departament Orthopedics and Traumatology: modern orthopedics
}

\author{
Marco Kawamura Demange ${ }^{1}$, Olavo Pires de Camargo ${ }^{2}$, \\ Tarcisio Eloy Pessoa de Barros Filho², Gilberto Luis Camanho
}

\section{Modern Orthopedics: A New Era?}

The word "Orthopedia" was used for the first time as the title of book published in 1741 by Nicholas Andry, Professor of Medicine at the University of Paris, formed by the combination of two words "orthos" (meaning straight) and "paidios" (meaning child). Originally, the orthopedists were primary concerned with the treatment of childhood deformities, with less understanding of the treatment of degenerative diseases, trauma, and tumors. In the present, Orthopedic Surgery is a completely different medical specialty. In the modern world, with the aging of the population, musculoskeletal diseases are becoming a huge burden ${ }^{1}$. Musculoskeletal disease is among the most common causes of severe long-term disability and practical pain in industrialized societies . Sports injuries and musculoskeletal trauma condition had become more frequent in the modern world.

The impact and importance of musculoskeletal diseases are critical not only for individual health and mobility but also for social functioning and productivity and economic growth on a larger scale, reflected by the proclamation of the Bone and Join Decade 2000-2010². Patients and population desire fast recovery and quality of life regarding any musculoskeletal conditions.

In the last two decades, orthopedic surgery had deeply changed in several areas. There had been a huge development in trauma care, joint replacement, spine surgeries, microsurgery, arthroscopy (video assisted surgery), and tumor care. Also, there is a strong trend to less invasive, more biological, and fast recovery approach in the treatment of orthopedic conditions ${ }^{3}$.

\section{Fast-recovery, pain control and video-assisted surgery}

In the old days, orthopedic procedures were known to cause long rehabilitation period, with several patients being restricted to bed or non-ambulatory for a long period of time. The current trend in orthopedics is "Fast-Recovery", both regarding hospital discharge and returning to "normal" life activities ${ }^{4,5}$. Several approaches have been responsible for faster recovery, especially featuring modern implants, video-assisted surgery, minimally invasive as well as percutaneous surgical procedures, and better pain-control methods.

The first arthroscope was made by Takagi in 1931 . Initially, this procedure was restricted to evaluating the knee joint. Nowadays, most sports medicine procedures

1. Professor Doctor of the Department of the Orthopedics and Traumatology of the Faculdade de Medicina da Universidade de São Paulo-DOT-FMUSP. Email: demange@me.com.

2. Full Professor of the Department of the Orthopedics and Traumatology of the Faculdade de Medicina da Universidade de São Paulo_DOT-FMUSP.Emails: olapcama@uol.com.br, pebarros@globo.com, gilbertocamanho@gmail.com

Mailing address: Departamento de Ortopedia e Traumatologia da FMUSP. Rua Ovidio Pires de Campos, 333 - $3^{\circ}$ andar. São Paulo, SP, Brasil. 
are performed with the aim of arthroscopes. Recently, endoscopic spine surgery is growing in order to provide less invasive and fast recovery surgical procedures ${ }^{6}$. Also, the evolution of technological equipment for radioscopy allowed smaller surgical incisions and less surgical trauma, resulting in faster patient recovery.

Pain control has been on the focus of orthopedic surgery in the last decade. ${ }^{7}$ Minimally invasive approach in orthopedic surgery includes pain control and blood management. Several approaches had been described to decrease post operative pain and allow faster recovery. ${ }^{8} 9$ Multimodal pain control approach, less traumatic interventions and early rehabilitation protocols are part of "fast-recovery" $\operatorname{approach}^{10,11}$.

\section{Implants and Joint Replacement}

Modern orthopedic surgical technique is strongly related to the development of new implants. Trauma surgery, joint replacement, sports medicine surgery, and spine surgery had strongly benefit from the implant development.

In 1958 a group of Swiss general and orthopaedic surgeons established the AO (Arbeitsgemeinschaft fur Osteosynthesefragen) or the Association of the Study of Internal Fixation (ASIF) with the objective of transform the contemporary treatment of fractures. Through a process of internal quality control (AO documentation) the clinical success of these new techniques and implants became evident. Operative fracture treatment gained more acceptance worldwide ${ }^{12}$.

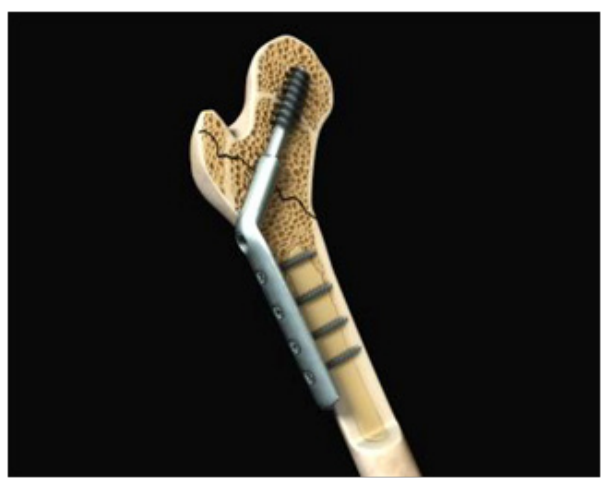

Figure 1. Example of fracture treated with internal fixation and implant

Joint degenerative diseases cause disability and life quality impairment. Also, elder patients with hip fracture seldom need to be treated with a hip replacement surgery for this life threatening condition. The total hip replacement has been intensively developed after 1960s with very good long term results. Better materials, better designs, better implant to bone integration and improvement in the surgical technique have enhanced its results. Recently, total hip replacement has been considered by at the Lancet journal as "the operation of the century"13.

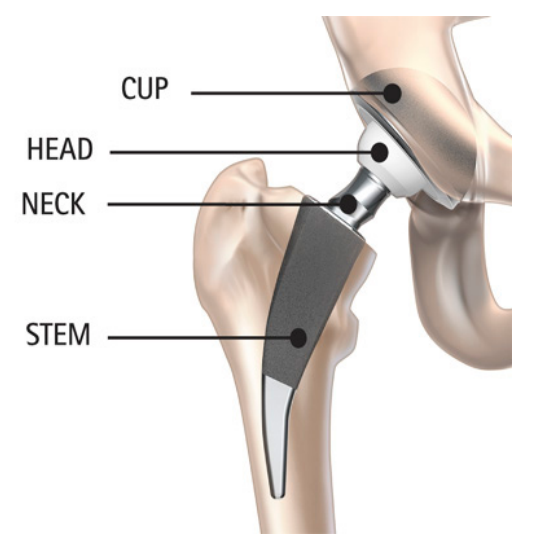

Figure 2. Example of a total hip arthroplasty surgery

In parallel, knee replacement has also been strongly developed. The number of knee joint replacement surgery had been growing every year. In the beginning of this century, around 200.000 total knee arthroplasties were performed per year in the United States of America. In 2015, there were more than one million total knee replacement surgeries, and it is expected to be more than 3 million by the year of $2030^{14,15}$. There is no reliable data regarding the number of total knee arthroplasties Brazil, but the number of surgeries is noticeably increasing. Better implants, better surgical technique and more effective peri-operative approaches lead to a longer survivorship and much better outcomes of total knee replacement.
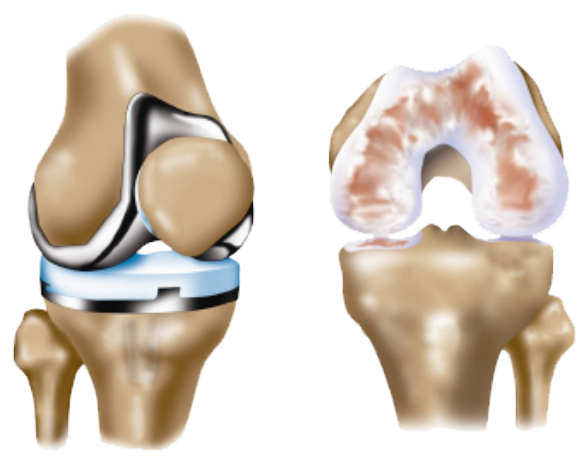

Figure 3. Example of a Total Knee Replacement (left) and arthritic knee (right) 
Evolution of biomaterials had incorporated biologically active components and had been developed in parallel and combined with the application of more biological approaches in orthopedic surgery ${ }^{16,17}$. Biotechnologies and biomaterials are incorporated to orthopedic surgery to increase the effectiveness of the treatment. Biomaterials and tissue engineering are fields of growing interest ${ }^{18}$.

\section{Computer Assisted Surgery and Robotics}

Orthopedic surgery frequently demands to be performed as precisely as possible. Surgeries involving tumor resections, limb alignment, implant component, fracture reduction, or musculoskeletal reconstructions need to be performed with accuracy. Computer-assisted orthopedic surgery (CAOS) and navigation applications have a history rooted in the desire to link imaging technology with real-time anatomic landmarks. Computerassisted orthopedic surgery has been proposed to potentially improve the surgeon's accuracy, reproducibility, and in reducing outlier outcomes ${ }^{19}$. Most applications of CAOS have been primarily in joint replacement surgery, spine surgery, and trauma ${ }^{20,21}$. Also, in orthopedic oncology, computer-assisted surgery (CAS) can be considered an alternative to fluoroscopy and direct measurement for orientation, planning, and margin control. ${ }^{22}$ Most of the development of the CAOS occurred during the 90's and 2000's, but there were some limitations regarding 3-D imaging, uploading patient data to the system and learning curve.

The use of robotic surgery has been growing in several fields in medicine. In the last decade, there has been several published researches on robotic assisted orthopedic surgeries ${ }^{23-25}$. Differently to other surgical fields, robotic-assisted surgeries, especially regarding joint replacements, had demonstrated a very short learning curve with more accurate surgical results ${ }^{24,25}$. The idea of more precise surgical procedures along with more accurate and reproducible surgeries encourage the development of robotic techniques in several areas of orthopedic surgery as spine surgeries and joint replacement ${ }^{26}$. Robotic-assisted surgery is very promising in orthopedics.

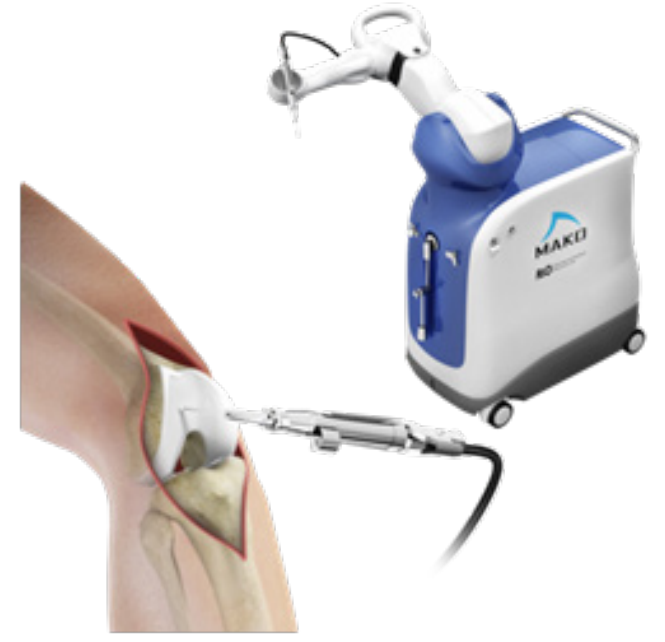

Figure 4. Example of robotic assisted knee surgery

\section{Biologics}

The use of biological approach in the orthopedic surgery is not recent. Osteochondral transplantation as well as bone grafting are not new procedure. On the other hand, there have been a significant improvement in the use of cell culturing and growth factor in the treatment of orthopedic conditions $^{27}$. For example, the use of cultured autologous chondrocytes to repair deep cartilage defects had been published in the New England Journal of Medicine in $1994^{28}$. There are various GMP facilities for cell culturing around the world and there is a lot of expectative regarding the use of cell culturing in the treatment various orthopedic conditions $^{29}$.

Researches regarding stem cell and pluripotent cells are also aimed in orthopedics. In 1867 the German pathologist Cohnheim hypothesized that nonhematopoietic, bone marrow-derived cells could migrate through the blood stream to distant sites of injury and participate in tissue regeneration. In 1868, the French physiologist Goujon studied the osteogenic potential of bone marrow on rabbits ${ }^{30}$. In 1991, Arnold Caplan had described the "mesenchymal stem cells" including its capacity of differentiate in bone, adipose tissue and cartilage $^{31}$. Recently, several studies demonstrate the immunomodulatory activity of "mesenchymal stem cells" increasing the possible utilization of these cells in orthopedics ${ }^{32,33}$. Also, several cytokines and growth factors 
had been better understood, which may strongly contribute for the development of a more biological approach in the orthopedic field ${ }^{34,35}$. Recently, Japanese scientist who started his career as orthopedic surgeon, Shinya Yamanaka proved that introduction of a small set of transcription factors into a differentiated cell was sufficient to revert the cell to a pluripotent state (iPS Cell). Yamanaka shared the Nobel Prize in Physiology or Medicine and opened a new door for potential applications of MSCs. This manuscript describes the concept of MSCs from the period when it was relegated to the imagination to the beginning of the twentyfirst century and their application in orthopaedic surgery ${ }^{36}$.

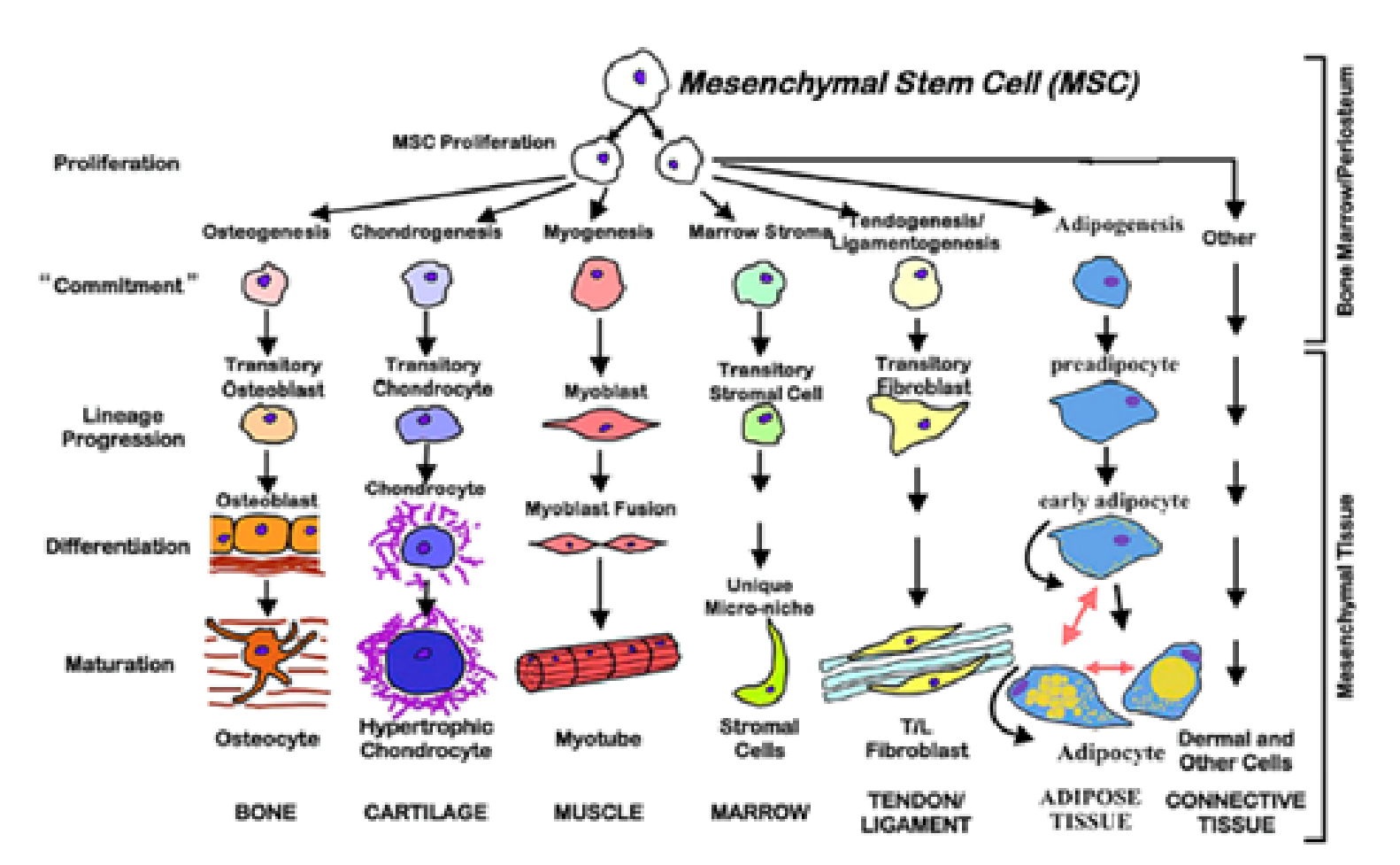

Figure 5.

Henry Mankin, Professor of Orthopedic Surgery at Harvard Medical School, stated that "future changes in orthopedics will be based in biology and more specifically in our ability to understand and alter the basic unit, the cell'".

\section{Conclusion}

Orthopedic surgery is in a huge changing process. It is hard to imagine how orthopedic surgery will be in future, but some trends are very clear: biological therapies, less invasive procedures allowing faster recovery, implants with biomaterials, robotic assisted procedures, and joint replacement surgery are definitely going to strongly influence orthopedics in the following years.

\section{REFERENCES}

1. Storheim K, Zwart JA. Musculoskeletal disorders and the Global Burden of Disease study. Ann Rheum Dis 2014;73:94950. doi: 10.1136/annrheumdis-2014-205327.

2. World Health Organization (WHO). Report of a WHO Scientific Group. The Burden of Musculoskeletal Conditions at the Start of the New Millennium. Geneve; 2003. p.218. (Technical Report Series, 919). Available from: http://apps. who.int/iris/bitstream/10665/42721/1/WHO_TRS_919.pdf.

3. Smith B, Goldstein T, Ekstein C. Biologic adjuvants and bone: current use in orthopedic surgery. Curr Rev Musculoskelet Med. 2015;8:193-9. doi: 10.1007/s12178-015-9265-z.

4. Banczerowski P, Czigleczki G, Papp Z, Veres R, Rappaport HZ, Vajda J. Minimally invasive spine surgery: systematic review. Neurosurg Rev. 2015;38(1):11-26; discussion. doi: 10.1007/s10143-014-0565-3.

5. Spetzger U, Von Schilling A, Winkler G, Wahrburg J, Konig A. The past, present and future of minimally invasive 
spine surgery: a review and speculative outlook. Minim Invasive Ther Allied Technol. 2013;22(4):227-41. doi: $10.3109 / 13645706.2013 .821414$.

6. Telfeian AE, Veeravagu A, Oyelese AA, Gokaslan ZL. A brief history of endoscopic spine surgery. Neurosurg Focus. 2016;40(2):E2. doi: 10.3171/2015.11.FOCUS15429.

7. Chamberlain D. New study suggests a better pain control option for orthopedic patients. Pain Manag. 2014;4:256.

8. Yuenyongviwat V, Pornrattanamaneewong C, Chinachoti T, Chareancholvanich K. Periarticular injection with bupivacaine for postoperative pain control in total knee replacement: a prospective randomized double-blind controlled trial. Adv Orthop. 2012;2012:107309.

9. Argintar E, Armstrong B, Zawadsky M, Evans B, Romness D. Pain control infusion pumps: a prospective randomized evaluation in bilateral total knee arthroplasty. Orthopedics. 2011;34:188.

10. Shin YS, Kim HJ, Ko YR, Yoon JR. Minimally invasive navigation-assisted versus conventional total knee arthroplasty: a meta-analysis. Knee Surg Sports Traumatol Arthrosc. 2016.

11. Tria AJ, Scuderi GR. Minimally invasive knee arthroplasty: An overview. World J Orthop. 2015;6:804-11.

12. Matter P. History of the AO and its global effect on operative fracture treatment. Clin Orthop Relat Res. 1998:11-8.

13. Learmonth ID, Young C, Rorabeck C. The operation of the century: total hip replacement. Lancet. 2007;370:1508-19.

14. Kurtz S, Mowat F, Ong K, Chan N, Lau E, Halpern M. Prevalence of primary and revision total hip and knee arthroplasty in the United States from 1990 through 2002. J Bone Joint Surg Am. 2005;87:1487-97.

15. Maradit Kremers H, Larson DR, Crowson CS, et al. Prevalence of Total Hip and Knee Replacement in the United States. J Bone Joint Surg Am. 2015;97:1386-97.

16. Huebsch N, Mooney DJ. Inspiration and application in the evolution of biomaterials. Nature. 2009;462:426-32.

17. Metsemakers WJ, Moriarty TF, Nijs S, Pape HC, Richards RG. Influence of implant properties and local delivery systems on the outcome in operative fracture care. Injury. 2016;47:595-604.

18. Vadala G, Russo F, Ambrosio L, Di Martino A, Papalia R, Denaro V. Biotechnologies and Biomaterials in Spine Surgery. J Biol Regul Homeost Agents. 2015;29:137-47.

19. Jackson DW, Simon TM. History of computer-assisted orthopedic surgery (CAOS) in sports medicine. Sports Med Arthrosc. 2008;16:62-6.

20. Zheng G, Nolte LP. Computer-Assisted Orthopedic Surgery: Current State and Future Perspective. Front Surg. 2015;2:66.

21. Radermacher K, Tingart M. Computer-assisted orthopedic surgery. Biomed Tech (Berl). 2012;57:207.
22. Gerbers JG, Stevens M, Ploegmakers JJ, Bulstra SK, Jutte PC. Computer-assisted surgery in orthopedic oncology. Acta Orthop. 2014;85:663-9.

23. Banerjee S, Cherian JJ, Elmallah RK, Jauregui JJ, Pierce TP, Mont MA. Robotic-assisted knee arthroplasty. Expert Rev Med Devices. 2015;12:727-35.

24. Karia M, Masjedi M, Andrews B, Jaffry Z, Cobb J. Robotic assistance enables inexperienced surgeons to perform unicompartmental knee arthroplasties on dry bone models with accuracy superior to conventional methods. Adv Orthop. 2013;2013:481039.

25. Citak M, Suero EM, Citak M, et al. Unicompartmental knee arthroplasty: is robotic technology more accurate than conventional technique? Knee. 2013;20:268-71.

26. Lonjon N, Chan-Seng E, Costalat V, Bonnafoux B, Vassal M, Boetto J. Robot-assisted spine surgery: feasibility study through a prospective case-matched analysis. Eur Spine J. 2016;25:947-55.

27. Leon L, Abasolo L, Carmona L, et al. Orthopedic surgery in rheumatoid arthritis in the era of biologic therapy. J Rheumatol. 2013;40:1850-5.

28. Brittberg M, Lindahl A, Nilsson A, Ohlsson C, Isaksson O, Peterson L. Treatment of deep cartilage defects in the knee with autologous chondrocyte transplantation. N Engl J Med. 1994;331:889-95.

29. Goldschlager T, Oehme D, Ghosh P, Zannettino A, Rosenfeld JV, Jenkin G. Current and future applications for stem cell therapies in spine surgery. Curr Stem Cell Res Ther. 2013;8:381-93.

30. Hernigou P. Bone transplantation and tissue engineering, part IV. Mesenchymal stem cells: history in orthopedic surgery from Cohnheim and Goujon to the Nobel Prize of Yamanaka. Int Orthop. 2015;39:807-17.

31. Caplan AI. Mesenchymal stem cells. J Orthop Res 1991;9:64150.

32. Kaplan JM, Youd ME, Lodie TA. Immunomodulatory activity of mesenchymal stem cells. Curr Stem Cell Res Ther. 2011;6:297-316.

33. Caplan AI. Adult Mesenchymal Stem Cells: When, Where, and How. Stem Cells Int. 2015;2015:628767.

34. Demange MK, de Almeida AM, Rodeo SA. Updates in biological therapies for knee injuries: tendons. Curr Rev Musculoskelet Med. 2014;7:239-46.

35. Demange MK, Sisto M, Rodeo S. Future trends for unicompartmental arthritis of the knee: injectables \& stem cells. Clin Sports Med. 2014;33:161-74.

36. Nobel Prize in Physiology or Medicine 2012 Nobel Media AB 2013. 